\title{
Holding On: A Community Approach to Autonomy in Dementia
}

\author{
Kit Rempala \\ Loyola University Chicago \\ Marley Hornewer \\ The University Of Michigan \\ Joseph Vukov \\ Loyola University Chicago, jvukov@luc.edu \\ Rohan Meda \\ Loyola University Chicago \\ Sarah Khan \\ Loyola University Chicago \\ Follow this and additional works at: https://ecommons.luc.edu/philosophy_facpubs \\ Part of the Philosophy Commons

\section{Author Manuscript} \\ This is a pre-publication author manuscript of the final, published article.
}

\section{Recommended Citation}

Rempala, Kit; Hornewer, Marley; Vukov, Joseph; Meda, Rohan; and Khan, Sarah. Holding On: A Community Approach to Autonomy in Dementia. American Journal of Bioethics, 20, 8: 107-109, 2020. Retrieved from Loyola eCommons, Philosophy: Faculty Publications and Other Works, http://dx.doi.org/10.1080/ 15265161.2020.1781971

This Article is brought to you for free and open access by the Faculty Publications and Other Works by Department at Loyola eCommons. It has been accepted for inclusion in Philosophy: Faculty Publications and Other Works by an authorized administrator of Loyola eCommons. For more information, please contact ecommons@luc.edu. cc) (i) $\Theta$

This work is licensed under a Creative Commons Attribution-Noncommercial-No Derivative Works 3.0 License.

(c) Taylor \& Francis, 2020. 


\title{
Holding On: A Community Approach to Autonomy in Dementia
}

\author{
Kit Rempala a Marley Hornewer ${ }^{b}$, Joseph Vukova ${ }^{a}$, Rohan Meda ${ }^{a}$, and Sarah Khan ${ }^{a}$ \\ ${ }^{a}$ Loyola University Chicago; bUniversity of Michigan
}

Walsh problematizes a dichotomy in medical decision-making for dementia patients: clinical practice tends to give moral weight to patients' post-onset preferences, while philosophical literature tends to argue for the prioritization of advance directives. Walsh refutes the philosophical view in favor of common clinical practice by considering Dworkin's endorsement of advance directives as "an effective means of extending an individual's autonomy from their current self, as an individual who has decisional capacity, onto their future self, who lacks it" (Walsh 54). Dworkin proposes that the changing, contradicting, and/or "whimsical" preferences characteristic of dementia patients do not reflect autonomously established critical interests—and thus necessitate prioritization of advance directives in medical decision-making. In sum: Dworkin's view of autonomy requires both a patient's ability to form critical interests and that critical interests "show a degree of stability and resistance to change across time" (58).

Responding to Dworkin's view, Walsh argues that a patient's change in preferences throughout the experience of dementia is insufficient reason to assume post-onset preferences are inauthentic, nonautonomous, or bear less moral weight. Walsh likens dementia to Paul's (2016) concept of a cognitive transformative experience. Given that the transformative experience changes "the way the person thinks about their preferences, values, and beliefs" (Walsh 2020, 59), Walsh asserts the implications of dementia "could not be fully considered by someone who is in a process of drawing up an advance directive" (55).

In this commentary, we (i) affirm and elaborate on Walsh's position using Agnieszka Jaworska's (2017) idea that dementia patients— despite having diminished autonomy—are still "valuers" (280) who can originate and maintain critical interests. We then (ii) introduce Hilde Lindemann Nelson's (2002) concept of "holding the individual in personhood" (Nelson 30), to (iii) evaluate Walsh's account using Nelson's framework.

Consider first Jaworska's account of autonomy, according to which the "potential for autonomy [is associated] primarily with the capacity to value, and well-being with living in accordance with one's values" (276). Being a valuer, according to Jaworska, requires only that the person "thinks he is correct in wanting what he wants, and achieving what he wants is tied up with his sense of self-worth" (280). By these criteria, dementia patients are indeed "valuers," and can maintain partial autonomy through their ability to value. Jaworska's account of autonomy thus functions as an alternative to Dworkin's account that dementia patients' diminished capability to originate and maintain critical interest deprives them of autonomy.

Likewise, for Jaworska, critical interests need not require a profound sense of what it means to live a good life as a whole, but merely opinions about what is good and how to live well (278-9). Jaworska states, "anyone who has a conception of himself, a set of ideals that he wants to live up to and in virtue of which he 
assesses his own value, is no doubt a valuer" (280). On this view, even if dementia undermines previous, more complex interests, the values those interests entailed may survive as simpler, reconfigured critical interests which deserve equal moral consideration (278). Here, Jaworska's account supports Walsh's, according to whom transformative experiences may drastically alter patients' preferences/critical interests, but do not necessarily discount their stability and validity (Walsh 2020).

In agreement with Walsh, we posit that while dementia unarguably compromises the patient's autonomy, this does not mean it is in the patient's best interests to disregard whatever autonomy remains in favor of deference to a previously-drafted advanced directive. Moreover, in agreement with Jaworska, we posit that the reason for such lies in the fact that the advance directive may not reflect the patient's current critical interests as a valuer.

But where to go from here? In the remainder of this commentary, we build on Walsh's and Jaworska's accounts by advocating for a medical decision-making process that emphasizes and supplements dementia patients' remaining autonomy via community engagement. By understanding autonomy as a community effort, we support the central idea behind both Walsh's and Jaworska's accounts: “To properly respect the autonomy of many an Alzheimer's patient, one must do quite a bit to enhance his autonomy. One must help the person no longer able to do so on his own lead his life according to his remaining values, to the extent that this is still feasible" (Jaworska 288).

Consider Hilde Lindemann Nelson's (2002) concept of "holding the individual in personhood" (Nelson 30). On Nelson's account, family/caregivers can construct or maintain "a personal identity for [a person] when she cannot, or can no longer, do it for herself" (30). Nelson develops her view with an eye to cases like vegetative states, anencephalic infants, and Alzheimer's patients. Applied to cases of dementia, Nelson's view implies that dementia patients' autonomy can be "held in place" via community-constituted efforts, which would adequately nullify necessary deference to advance directives.

For Nelson, personhood — as made possible through mutual recognition of and response to narrative identity - is important because identities "stand surrogate for how those who bear them may be treated" (31). Patients who experience dementia-instigated narrative discontinuity, such as Walsh's account of Wendy Mitchell describing her pre- and post-dementia selves as separate people (Walsh 2020), are thus at risk of being regarded as incomplete persons. It is precisely this fact that often motivates deferring to advance directives which were written in a state of more complete personhood. Nelson's account of personhood, however, provides the foundation for the morally superior alternative defended by Walsh and Jaworska. Nelson's account shows how a community can bolster an individual's diminished personhood. More particularly, a communal recognition of an individual's "changing procession of sensations, emotions, beliefs, attitudes, wishes, misgivings, and other mental states," and care providers' acting in accordance with these preferences/values, can serve to supplement an individual's identity (34). Nelson's account of personhood thus grounds Jaworska's view that to be a valuer does not require narrative continuity or a "sense of one's life 
as a whole" (278), but only a "confluence between thinking about and acting upon what you say you value and your emotional life" (283).

Grounding Walsh's and Jaworska's accounts on Nelson's account of "holding individuals in personhood" also has another implication—one that is brought out by neither Walsh nor Jaworska themselves. In particular, dementia patients' emotional capacity to value or convey interests, along with these other constituting mental states, may not on their own be sufficient for full autonomy. However, within the framework of a community which (i) establishes common attitudes regarding the individual's current preferences/critical interests, (ii) shares a recognition that the individual has "certain rights, [and] is properly the object of various moral duties" (Nelson 33), and (iii) contributes actions/treatments to the individual's life which are in accordance with the individual's values, we contend a demented individual's autonomy/ critical interests can be "held in place" without the need for advance directives. Thinking in this way, then, "rather than tying personhood solely to capabilities and competencies residing within the individual, we have to see it as partly also an interpersonal achievement" (34 [emphasis ours]).

By comparison, the upholding of advance directives threatens a form of "holding in place" in which the preferences of an individual's pre-transformative-experience identity supersede the preferences of the post-transformative-experience identity—and doing so undermines the patient's current values. In the model we have presented, however, caretakers can supplement/reconstitute dementia patients' diminished autonomies and fulfill patients' critical interests, without sacrificing the patients' current values or the quality of their current life experience. We argue that the community-centric approach we advocate here therefore represents a morally superior alternative to advance directives, as it undermines neither previous nor remaining autonomy, and does not "hold in place" an identity which no longer fits the demented individual.

\section{References:}

Jaworska, A. 2017. Ethical dilemmas in neurodegenerative disease: Respecting patients at the twilight of agency. In J. Illes, ed., Neuroethics: Anticipating the future. Oxford, UK: Oxford University Press, 274-293.

Nelson, H. L. 2002. What child is this? The Hastings Center Report 32(6): 29-38.

Walsh, E. 2020. Cognitive transformation, dementia, and the moral weight of advance directives. The American Journal of Bioethics 20(8): 54-64. 